\title{
Avaliação de desempenho do reator UASB no tratamento do efluente da Universidade Federal de Sergipe
}

\section{Evaluation of performance of the UASB reactor in the treatment of the effluent of Federal University of Sergipe}

Data de entrada: 01/07/2019

Data de aprovação: 29/10/2019

Lucio Vinícius Aragão Santos' ${ }^{1}$ Sérgio Souza Oliveira² | Arnon Sillas Novais Souza' | Denise Conceição de Gois Santos Michelan ${ }^{1 *}$

DOI: https://doi.org/10.36659/dae.2020.092

ORCID ID

Santos LVA (D) https://orcid.org/0000-0002-6487-1134

Oliveira SS (D) https://orcid.org/0000-0002-7241-8073

Souza ASN (D) https://orcid.org/0000-0003-0600-2990 Michelan DCGS (D) https://orcid.org/0000-0003-0091-8826

\section{Resumo}

O estudo se baseou na avaliação do reator UASB, da ETE da Universidade Federal de Sergipe, qualitativa e quantitativamente, condições operacionais e eficiência. O monitoramento ocorreu em 10 campanhas, com base em DQO, sólidos (totais, suspensos e sedimentáveis), nitrogênio, fósforo, pH e temperatura. Como resultados observou-se que o $\mathrm{pH}$ e a temperatura variaram de acordo com o indicado para digestão anaeróbia. Com relação à remoção de matéria orgânica expressa em DQQ e sólidos observaram-se valores abaixo do esperado, em torno de $25,4 \%$ e $10 \%$, respectivamente, atrelados tanto à descontinuidade na alimentação do reator como ao processo ineficiente de inoculação de lodo ativo no início da operação do sistema. A eficiência observada de remoção de nutrientes foi baixa e o tempo de detenção de $60 \mathrm{~h}$. Com isso, conclui-se que a operação não ocorre de forma adequada.

Palavras-chave: Saneamento. Digestão anaeróbia. Águas residuais.

\section{Abstract}

The study was based on UASB reactor assessment of ETE at the Federal University of Sergipe, qualitatively and quantitatively, operating conditions and efficiency. The monitoring occurred in 10 campaigns, based on COD, solids (total, suspended and sedimentary), nitrogen, phosphorus, $\mathrm{pH}$, and temperature. The results showed that $\mathrm{pH}$ and temperature varied according to the indicated for anaerobic digestion. Regarding the removal of organic matter expressed in COD and solid values, it was below the expected, around $25.4 \%$ and $10 \%$, respectively, raised both the discontinuity in the reactor's power, as the inefficient process of sludge inoculum active in the beginning of the operation of the system. The observed nutrient removal efficiency was low and the time of arrest of $60 \mathrm{~h}$ with this it is concluded that the operation does not occur properly.

Keywords: Sanitation. Anaerobic digestion. Residual waters.

\footnotetext{
${ }^{1}$ Universidade Federal de Sergipe - São Cristóvão - Sergipe - Brasil.

${ }^{2}$ Instituto Federal de Sergipe (IFS) - Aracaju - Sergipe - Brasil.

* Autora correspondente: denise_goisayahoo.com.br.
} 


\section{INTRODUÇÃO}

O saneamento básico apresenta-se como peça fundamental para a interrupção do ciclo da pobreza, reduzindo a proliferação de doenças, a desnutrição e a perda da população economicamente produtiva direta e indiretamente, além de promover o desenvolvimento sustentável por meio de políticas conscientes e da manutenção dos recursos naturais (WWAP, 2017).

Segundo dados do Sistema Nacional de Informações sobre Saneamento (SNIS), até 2017 menos de $61 \%$ das cidades brasileiras possuíam coleta de esgoto. $E$, desses $61 \%$ de esgotos coletados, somente $46 \%$ possuíam tratamento, o que se mostra uma situação bastante crítica, considerada um problema de saúde pública (SNIS, 2019). O estado de Sergipe possui uma realidade ainda mais alarmante em relação à média do país, com cobertura de $32 \%$ de esgoto (ANA, 2017).

Uma das ferramentas fundamentais do saneamento na prevenção da saúde e na proteção dos recursos hídricos é o tratamento de esgoto, uma vez que o efluente sendo lançado in natura nos corpos d'água pode ocasionar problemas à qualidade da água e seu tratamento resultará em serviço de abastecimento seguro para população, na manutenção do bioma aquático e no equilíbrio geral do meio (NUVOLARI et al., 2011).

Devido a esse cenário, foi necessário buscar opções que viabilizassem o tratamento das expressivas taxas de efluentes que passaram a ser geradas. Dentre as diversas formas de tratamento existentes, o reator de Fluxo Ascendente de Manta de Lodo (Upflow Anaerobic Sludge Blanket - UASB) apresenta-se como alternativa, principalmente em países de clima tropical e que estão em processo de desenvolvimento, como o Brasil (JORDÃO; PÊSSOA, 2014).

Esses sistemas devem ser operados com elevados tempos de retenção de sólidos (TRS) e baixíssimos tempos de detenção hidráulica (TDH) a fim de conferir aos mesmos potencial para a sua aplicabilidade no tratamento de efluentes de baixa concentração. Esse parâmetro geralmente varia entre 4 e 10 horas, a depender da temperatura utilizada no tratamento do esgoto doméstico (CAMPOS, 1999). Além disso, as principais vantagens são baixo consumo energético, baixo custo com operação, baixo requisito de área, além da reduzida produção de lodo e geração de biogás (CHERNICHARO et al., 2015; VON SPERLING, 2014).

Entretanto, o curto tempo de detenção do efluente no reator pode prejudicar o funcionamento do sistema em relação aos aspectos: perda excessiva de biomassa, redução do tempo de residência celular (idade do lodo) e possibilidade de falha do sistema. Além disso, a remoção de patógenos e nutrientes é somente parcial. Por isso uma unidade de pós-tratamento é requerida, principalmente se houver o propósito de reúso desse efluente (CHONG et al., 2012).

O projeto de reatores UASB é simples e não requer a instalação de qualquer dispositivo ou meio de vedação para fixação e retenção de biomassa (JORDÃO; PESSÔA, 2014). O dispositivo de separação trifásica (sólido-líquido-gás) presente no interior do reator, além de garantir o retorno da biomassa (lodo) que se desprendeu e afluiu junto com a massa líquida, proporciona ao sistema alta capacidade de retenção de grandes quantidades de biomassa, de elevada atividade, fazendo com que a estabilização do lodo ocorra no próprio reator (CAMPOS, 1999).

É notório que as universidades, atualmente, podem ser comparadas com pequenos núcleos urbanos e contribuem por meio de diversas atividades para a geração de efluentes. Dessa forma, diversos Campi passaram a investir em infraestrutura básica, como, por exemplo, sistemas de coleta de esgoto aliados a estações de tratamento de efluentes, a fim de direcionar e tratar o passivo doméstico gerado por esses centros (TAUCHEN; BRANDLI, 2006; HELLER; NASCIMENTO, 2005). 
Em virtude disso, a Estação de Tratamento de Efluentes (ETE) da Universidade Federal de Sergipe (UFS), em operação desde 2015, composta de tratamento biológico anaeróbio do tipo UASB, compreende o tratamento secundário da estação.

Assim, o presente trabalho buscou avaliar qualitativa e quantitativamente o esgoto afluente e efluente ao reator UASB da UFS, a fim de conhecer as condições operacionais do sistema e consequentemente determinar a eficiência do reator por meio de monitoramento de parâmetros químicos, físicos e operacionais.

\section{METODOLOGIA}

\subsection{Caracterização da Área de Estudo}

A área de estudo, como pode ser visualizado na Fig. 1, situa-se na Cidade Universitária “Prof. José
Aloísio de Campos", localizada na Avenida Marechal Rondon, s/n - Bairro Jardim Rosa Elze, São Cristóvão, Sergipe. Inicialmente, o tratamento de efluente da Universidade Federal de Sergipe era realizado por lagoas de estabilização. Porém, em novembro de 2011, foi dado início, no Projeto Executivo, a um novo sistema de esgotamento sanitário, com tratamento e disposição das águas residuárias de todo o Campus. Assim, em junho de 2015, a Estação de Tratamento da UFS foi concluída. Essa unidade é composta por tratamento preliminar, composto por: gradeamento e desarenação. $O$ efluente, após passar pelo tratamento preliminar, é direcionado para uma $\mathrm{Ca}$ Iha Parshall de 3" de largura de garganta, onde ocorre a medição da vazão afluente. Em seguida o esgoto é encaminhado a uma estação elevatória, na qual ficam acomodadas duas bombas de recalque com operação alternada.

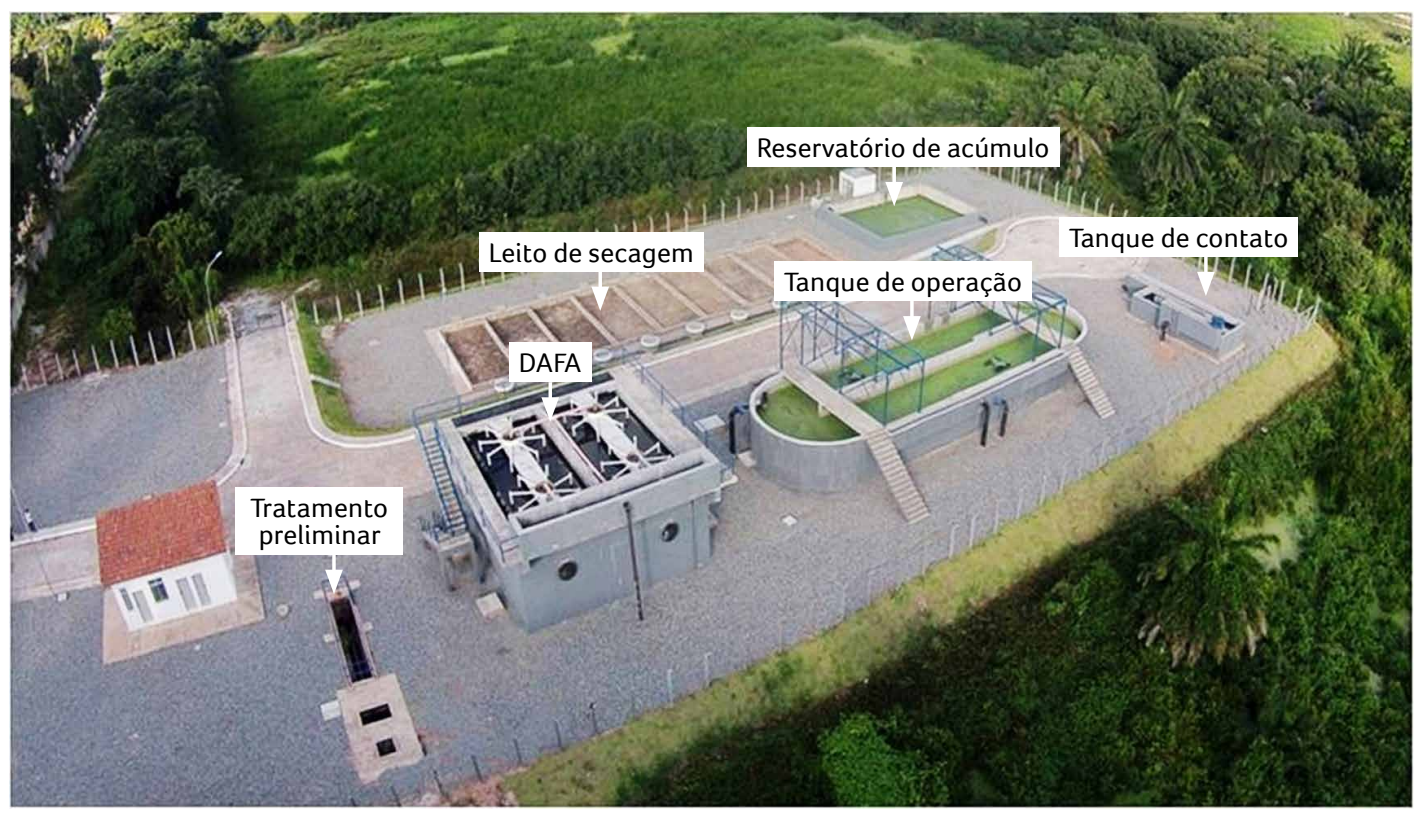

Figura 1 - Disposição da Estação de Tratamento de Efluente da Universidade Federal de Sergipe (Composto por Tratamento Preliminar, Reator UASB ou DAFA, Lodo Ativado ou tanque de operação, Tanque de Contato, Reservatório de Acúmulo e Leito de Secagem)

Fonte: Adaptado de Menezes (2016) 
O efluente segue para as etapas de tratamento biológico anaeróbio e aeróbio, respectivamente, composta por Reator Anaeróbio de Fluxo Ascendente seguido de Lodo Ativado. Essa configuração deve ser avaliada com bastante atenção, já que apresenta boa remoção de matéria orgânica, sólidos em suspensão e amônia, porém praticamente não apresenta eficiência significativa na remoção dos nutrientes (CHERNICHARO, 2006).

O reator anaeróbio da estação de tratamento da UFS possui as seguintes dimensões de projeto: $10 \mathrm{~m}$ de comprimento, $10 \mathrm{~m}$ de largura e $5,1 \mathrm{~m}$ de altura útil, resultando em um volume útil de $510 \mathrm{~m}^{3}$. Para construção dessa etapa foi utilizado concreto armado, com revestimento interno à base de policloreto de vinila (PVC) para proteção anticorrosiva, principalmente das paredes e lajes que ficam em contato com o líquido. $O$ processo de digestão anaeróbia ocorre no fundo do reator com a formação e manutenção da manta de lodo, onde microrganismos anaeróbios transformam a matéria orgânica carbonácea do afluente em produtos estabilizados. O gás metano que é gerado no processo é direcionado por um defletor a um coletor de gás que em seguida o direciona para um queimador de gás, localizado no fundo da estação.

Já a etapa aeróbia possui um reator com volume útil de 559,80 $\mathrm{m}^{3}$, no qual microrganismos aeróbios espalhados ao longo do reator utilizam oxigênio proveniente de dois aeradores superficiais de $7,46 \mathrm{~kW}$ a fim de realizar a degradação da matéria orgânica proveniente do processo anaeróbio.

Por fim, o efluente é direcionado para a etapa de desinfecção, representada por um tanque de contato, dotado de chicanas de forma a garantir o tempo de contato de 30 minutos. A neutralização dos microrganismos patogênicos ocorre por meio da adição do hipoclorito de sódio ativo a $12 \%$. Após a desinfecção, o efluente é enviado ao reservatório de acúmulo e então direcionado ao rio Poxim (Sergipe). $O$ efluente deve possuir parâmetros de acordo com as exigências feitas pela legislação Conama 430 (BRASIL, 2011). A ETE conta com nove leitos de secagem, para onde são direcionados os volumes de lodo excedente, proveniente dos reatores anaeróbio e aeróbio. Após a secagem, o lodo é estabilizado, coletado e direcionado para Estação de Recuperação de Qualidade (ERQ̨) Norte, localizada no município de Nossa Senhora do Socorro, Sergipe e operada pela Companhia de Saneamento do Estado de Sergipe (DESO).

\subsection{Período de Monitoramento e análises físico-químicas}

As coletas das amostras foram realizadas à montante e a jusante do reator UASB (afluente e efluente, respectivamente), durante o período da manhã entre os meses de maio/2018 a julho/2018, perfazendo 10 campanhas.

As análises utilizadas para a avaliação da eficiência do reator UASB foram: demanda química de oxigênio (DQO), sólidos totais (ST), suspensos (SS) e sedimentáveis (SSED), temperatura e $\mathrm{pH}$, nitrogênio total e fósforo total. Essas análises foram processadas em duplicatas e a maioria dos procedimentos executados seguiu a metodologia proposta pelo APHA (2012) ou referência indicada pelo equipamento utilizado na análise. As análises desenvolvidas estão citadas na Tabela 1, bem como os métodos analíticos. 
Tabela 1 - Análises realizadas e método utilizado em cada ponto

\begin{tabular}{|c|c|c|}
\hline Parâmetro/Análise & Abreviação & Método/Modelo \\
\hline Potencial Hidrogeniônico & $\mathrm{pH}$ & Químis Q400 A \\
\hline Sólidos Totais & ST & SMEWW' $^{1} 2540 \mathrm{~B}$ \\
\hline Sólidos Suspensos & SS & SMEWW' $^{\prime} 2540$ D \\
\hline Sólidos Sedimentáveis & SD & SMEWW' $^{1} 2540 \mathrm{~F}$ \\
\hline Demanda Química Oxigênio & DQO & 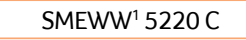 \\
\hline Nitrogênio Total & NT & SMEWW' $4500-$ Norg B \\
\hline Fósforo Total & FT & SMEWW'1 4500-P D \\
\hline Temperatura & $\mathrm{T}$ & Termômetro L.228/07 \\
\hline
\end{tabular}

${ }^{1}$ Standard Methods for the Examination of Water and Wastewater $22^{\text {nd }}$ Edition

\subsection{Critérios Operacionais}

De posse dos dados quantitativos e qualitativos, foi possível determinar as condições operacionais do reator UASB. Os parâmetros analisados foram: carga hidráulica volumétrica (CHV), tempo de detenção hidráulica (TDH) e velocidade ascensional do fluxo (V). Esses parâmetros foram avaliados a partir do Programa de Pesquisas em Saneamento Básico - Prosab (CAMPOS, 1999).

Para o cálculo da CHV, que é o volume diário afluente ingressante ao reator por unidade de volume, foi utilizado o valor de vazão média afluente ao reator em $\mathrm{m}^{3}$. dia ${ }^{-1}$. A CHV foi avaliada nas condições do sistema conforme a Eq. 1 .

$\mathrm{CHV}=\frac{Q}{V}\left(\mathrm{~m}^{3} / \mathrm{m}^{3} \cdot \mathrm{d}\right)$

onde: $Q$ = vazão $\left(\mathrm{m}^{3} / \mathrm{d}\right)$;

$V=$ volume total do reator $\left(\mathrm{m}^{3}\right)$.
Com relação ao TDH, este foi obtido como sendo o inverso da carga hidráulica volumétrica (Eq. 2).

$\mathrm{TDH}=\frac{1}{C H V}(\mathrm{~h})$

A velocidade ascensional do fluxo pode ser determinada com base na Equação da Continuidade (Eq. 3).

$\mathrm{v}=\frac{Q}{A}\left(\mathrm{~m} \cdot \mathrm{h}^{-1}\right)$

onde: $\mathrm{Q}=$ vazão $\left(\mathrm{m}^{3} \mathrm{~h}^{-1}\right)$;

$A=$ área da seção transversal do reator $\left(\mathrm{m}^{2}\right)$.

\section{RESULTADOS E DISCUSSÃO}

Os dados analíticos do esgoto afluente estão dispostos na Tabela 2.

Tabela 2 - Valores das variáveis obtidos nas análises de esgoto bruto

\begin{tabular}{|c|c|c|c|}
\hline \multirow{2}{*}{ Parâmetros } & \multicolumn{3}{|c|}{ Entrada do reator UASB } \\
\cline { 2 - 4 } & Média & Desvio Padrão & Variância \\
\hline DQO $\left(m g . \mathrm{L}^{-1}\right)$ & 144,90 & 33,95 & 1152,54 \\
\hline $\mathrm{ST}\left(\mathrm{mg} \cdot \mathrm{L}^{-1}\right)$ & 393,60 & 51,71 & 2674,27 \\
\hline $\mathrm{SS}\left(\mathrm{mg} \cdot \mathrm{L}^{-1}\right)$ & 60,57 & 30,25 & 915,08 \\
\hline $\mathrm{SSED}\left(\mathrm{mL} \cdot \mathrm{L}^{-1}\right)$ & 1,09 & 0,83 & 0,68 \\
\hline $\mathrm{pH}$ & 7,24 & 0,25 & 0,06 \\
\hline $\mathrm{T}\left({ }^{\circ} \mathrm{C}\right)$ & 28,2 & 0,9 & 0,8 \\
\hline $\mathrm{N}\left(\mathrm{mg} \cdot \mathrm{L}^{-1}\right)$ & 59,65 & 20,49 & 419,99 \\
\hline $\mathrm{P}\left(\mathrm{mg} \cdot \mathrm{L}^{-1}\right)$ & 2,88 & 1,78 & 3,18 \\
\hline
\end{tabular}


Com base na Tabela 2, pode-se verificar que a carga orgânica afluente ao reator se apresenta abaixo da faixa de valores típicos de concentração de DQQ no esgoto bruto, que é 250 a $1000 \mathrm{mg} \cdot \mathrm{L}^{-1}$ (METCALF, EDDY, 2015; VON SPERLING, 2014; JORDÃO; PESSÔA, 2014; LEME, 2014). O menorvalor de DQO afluente foi de $86,89 \mathrm{mg} \cdot \mathrm{L}^{-1}$, período da campanha que coincide com o recesso acadêmico no Campus, em virtude das festas juninas.

As concentrações de sólidos totais variaram entre 286,17 a 487,03 mg. $\mathrm{L}^{-1}$, já os sólidos suspensos variaram entre 28,84 e 109,17 mg. $\mathrm{L}^{-1}$, enquanto os sólidos sedimentáveis variaram de 0,33 a $3,12 \mathrm{~mL} \cdot \mathrm{L}^{-1}$. A literatura sugere faixa de concentração de 700 a $1350 \mathrm{mg} . \mathrm{L}^{-1}$ para os sólidos totais, de 200 a 450 mg. $\mathrm{L}^{-1}$ para os sólidos suspensos e de 10 a $20 \mathrm{~mL} . \mathrm{L}^{-1}$ para os sólidos sedimentáveis (BRASIL, 2015). As baixas concentrações observadas tanto para DQO como para sólidos foram possivelmente influenciadas pela contribuição de águas pluviais, infiltrações de água do lençol freático na rede através de poços de visita, uma vez que a campanha foi realizada entre os meses de maio e julho, o que corresponde ao período chuvoso para essa região (SILVA, 2001).

Em função do $\mathrm{pH}$ e da temperatura, de acordo com Campos (1999) os valores desses parâmetros no esgoto bruto variaram dentro da faixa sugerida pela literatura, sendo estas de 6,8 a 8,0 para o $\mathrm{pH}$ e de 25 a $35^{\circ} \mathrm{C}$ para a temperatura. $\mathrm{O}$ valor da mediana para o $\mathrm{pH}$ foi de 7,19 , e para a temperatura obteve-se média de $28,2^{\circ} \mathrm{C}$.

Já em termos de nitrogênio e fósforo, percebeuse que esses parâmetros variaram entre 32,88 e $87,78 \mathrm{mg} \cdot \mathrm{L}^{-1}$ e de 0,48 a $5,60 \mathrm{mg} \cdot \mathrm{L}^{-1}$, respectivamente. Enquanto a literatura apresenta valores típicos de concentração de nitrogênio entre 35 e $60 \mathrm{mg} \cdot \mathrm{L}^{-1}$, o fósforo varia entre 5 e $20 \mathrm{mg} \cdot \mathrm{L}^{-1}$. Vale ressaltar que a média para os valores de nitrogênio encontrados no esgoto bruto foi de $59,65 \mathrm{mg} . \mathrm{L}^{-1}$, enquanto para o fósforo foi de $2,89 \mathrm{mg} \cdot \mathrm{L}^{-1}$. Dessa forma percebe-se que os valores de nutrientes também estiveram dentro ou próximo das faixas indicadas pela literatura (METCALF, EDDY, 2014; VON SPERLING, 2014; JORDÃO; PESSÔA, 2014; LEME, 2014).

Em observação ao Manual de operação da ETE, onde cita que o campus possui contribuição de aproximadamente 25.000 pessoas, percebe-se que os problemas supracitados podem estar associados às características físico-químicas do esgoto bruto por apresentarem-se muito abaixo do que é citado na literatura para os parâmetros avaliados nesse trabalho. Quando se observam as características do efluente do campus do Morro do Cruzeiro, um dos três campi da Universidade de Ouro Preto, o qual possui contribuição em torno de 6.000 pessoas, o que corresponde a apenas $24 \%$ da população do campus de São Cristóvão, percebe-se que, apesar de possuir contribuição menor, os valores observados do esgoto bruto do campus mineiro, quando comparados aos mesmos parâmetros analisados neste trabalho, foram superiores. Valores de DQO no esgoto bruto do campus do Morro do Cruzeiro, por exemplo, apresentou valor médio de 403 mg.L ${ }^{-1}$ (BERTOLINO, 2007); já no efluente da UFS foi observado um valor médio de $144 \mathrm{mg} . \mathrm{L}^{-1}$. Como pode ser visto na Tabela 3, para ratificar essa informação, foram observadas características de efluentes brutos em trabalhos realizados em outras universidades no Brasil. Os valores médios observados foram $666 \mathrm{mg} \cdot \mathrm{L}^{-1}$ no Campus do Pici da Universidade Federal do Ceará (PEIXOTO, 2008), $388 \mathrm{mg} \cdot \mathrm{L}^{-1}$ no Campus da Universidade Federal do Rio de Janeiro (VERSIANI, 2005) e 566 mg. L $^{-1}$ no Campus I da Universidade de São Paulo (PASSIG, 2005). 
Tabela 3 - Valores média de DQQO de esgotos brutos em diferentes campi universitários

\begin{tabular}{|c|c|}
\hline Localização & $\begin{array}{c}\text { Efluentes brutos em } \\
\text { diferentes campus } \\
\text { Média de DQO total }\left(\mathbf{m g} \cdot \mathbf{L}^{\mathbf{1}} \mathbf{)}\right.\end{array}$ \\
\hline UFS/SE & 144 \\
\hline UFRJ/RJ & 388 \\
\hline MORRO DO CRUZEIRO/MG & 403 \\
\hline USP/SP & 566 \\
\hline UFC/CE & 666 \\
\hline
\end{tabular}

Na Tabela 4 estão dispostos os dados das variáveis obtidos na saída do reator. Em análise à Tabela 4, observou-se que o reator em termos de DQOO apresentou valor médio de $115,10 \mathrm{mg}^{\mathrm{L}} \mathrm{L}^{-1} \mathrm{e}$ desvio padrão de 50,42 mg. $\mathrm{L}^{-1}$. Além disso, observou-se para esse parâmetro na saída do reator valor mínimo de $39,78 \mathrm{mg} \cdot \mathrm{L}^{-1}$ e máximo de
198,81 mg.L-1 . Percebe-se que não houve variação acentuada, porém quando comparados com os dados de entrada do reator evidenciou-se que a eficiência média do sistema foi de $25,4 \%$ em termos de remoção de DQQO.

Em relação aos sólidos totais, o sistema apresentou na saída do reator valores mínimos de $316,63 \mathrm{mg} \cdot \mathrm{L}^{-1}$ e máximos de 509,38 $\mathrm{mg} \cdot \mathrm{L}^{-1}$. A média observada para esse parâmetro foi de $377,90 \mathrm{mg} \cdot \mathrm{L}^{-1}$ e desvio padrão de $63,34 \mathrm{mg} \cdot \mathrm{L}^{-1}$. Assim como a DQO, esse parâmetro apresentou variação relativamente baixa, no entanto a eficiência média do sistema na remoção dos ST foi de apenas, $9,67 \%$, semelhante à eficiência obtida por Araújo e Freitas (2014), que foi de 6\%.

Tabela 4 - Valores das variáveis obtidos nas análises de saída do reator

\begin{tabular}{|c|c|c|c|}
\hline \multirow{2}{*}{ Parâmetros } & \multicolumn{3}{|c|}{ Saída do reator UASB } \\
\cline { 2 - 4 } & Média & Desvio Padrão & Variância \\
\hline DQO $\left(m g . \mathrm{L}^{-1}\right)$ & 115,10 & 50,42 & 2542,10 \\
\hline $\mathrm{ST}\left(\mathrm{mg} \cdot \mathrm{L}^{-1}\right)$ & 377,90 & 63,34 & 4011,43 \\
\hline $\mathrm{SS}\left(\mathrm{mg} \cdot \mathrm{L}^{-1}\right)$ & 16,07 & 7,32 & 53,65 \\
\hline $\mathrm{SSED}\left(\mathrm{mL} \cdot \mathrm{L}^{-1}\right)$ & 0,14 & 0,07 & 0,00 \\
\hline $\mathrm{pH}$ & 7,74 & 0,21 & 0,042 \\
\hline $\mathrm{T}\left({ }^{\circ} \mathrm{C}\right)$ & 27,8 & 1,0 & 1,0 \\
\hline $\mathrm{N}\left(\mathrm{mg} \cdot \mathrm{L}^{-1}\right)$ & 59,92 & 18,02 & 324,88 \\
\hline $\mathrm{P}\left(\mathrm{mg} \cdot \mathrm{L}^{-1}\right)$ & 2,65 & 1,24 & 1,53 \\
\hline
\end{tabular}

Os resultados observados tanto para DQO como para ST indicam que de fato existem problemas relevantes no reator UASB, como pode ser observado no item 3.1.

Para o SS verificou-se valores que variaram entre 4,67 mg. $\mathrm{L}^{-1}$ e 27,67 mg. $\mathrm{L}^{-1}$, sendo que a média observada para esse parâmetro foi de $16,07 \mathrm{mg} \cdot \mathrm{L}^{-1}$ e desvio padrão de 7,32 mg. $\mathrm{L}^{-1}$. Em termos de eficiência quando comparados aos dados de entrada do reator, o sistema apresentou para esse parâmetro valores em torno de $68,27 \%$, semelhantes aos resultados encontrados por Von Sperling e Oliveira (2009), onde o sistema de tra- tamento composto por reator UASB apresentou capacidade de remoção de $67 \%$ de SS.

Os valores de $\mathrm{pH}$ e temperatura variaram dentro da faixa sugerida pela literatura para sistemas anaeróbios, com pH variando de 7,39 a 8,06; a temperatura variou entre $26,0^{\circ} \mathrm{C}$ a $29,3^{\circ} \mathrm{C}$.

Em relação ao nitrogênio, percebe-se que esse parâmetro apresentou valor mínimo de $37,17 \mathrm{mg} . \mathrm{L}^{-1}$ e máximo de $87,63 \mathrm{mg} \cdot \mathrm{L}^{-1}$, sendo que a média e o desvio padrão foram de 59,92 mg. $\mathrm{L}^{-1}$ e 18,02 mg. $\mathrm{L}^{-1}$, respectivamente. Já o fósforo apresentou valores que variaram entre 0,58 mg. $\mathrm{L}^{-1}$ a $4,24 \mathrm{mg} \cdot \mathrm{L}^{-1}$; a média e o desvio pa- 
drão foram 2,65 mg.L $\mathrm{L}^{-1}$ e 1,24 mg. $\mathrm{L}^{-1}$, respectivamente. Dessa forma, percebe-se que esses parâmetros não tiveram variação significativa ao longo da campanha. No entanto, o reator UASB em questão apresenta baixa eficiência na remoção desses parâmetros, como pode ser visto no item 3.3.
$\mathrm{Na}$ Tabela 5 estão dispostos os intervalos de concentração de efluentes e eficiências típicas de remoção, considerando sistemas devidamente projetados e operados. Também podem ser observados os valores de média e eficiência para a ETE UFS.

Tabela 5 - Faixa e eficiências exigidas pela Lei Conama 430/2011 e valores observados na ETE UFS

\begin{tabular}{|c|c|c|c|c|}
\hline \multirow{2}{*}{ Etapa do Tratamento } & \multirow{2}{*}{ Faixas de Eficiências } & \multicolumn{3}{|c|}{ Parâmetros } \\
\hline & & DQQ $\left(m g \cdot L^{-1}\right)$ & NT (mg. L-1) & PT (mg. $\left.\mathrm{L}^{-1}\right)$ \\
\hline \multirow{4}{*}{ Saída do Reator UASB } & Faixa Típica & 180 a 270 & $>20$ & $>4$ \\
\hline & Eficiência Típica (\%) & 55 a 70 & $<60$ & $<35$ \\
\hline & Média Observada & 115,1 & 59,92 & 2,65 \\
\hline & Eficiência Observada(\%) & 25,4 & 2,91 & 14,71 \\
\hline
\end{tabular}

Fonte: Adaptado de Chernicharo (2006)

\subsection{Remoção de Matéria Orgânica}

Com base nos dados de DQQO da Tabela 4, determinou-se a eficiência de remoção da matéria orgânica. Pode-se então perceber a baixa eficiência do reator. A mediana referente ao efluente do reator UASB apresentou $23,59 \%$ de eficiência na remoção de DQO. Já a média e o desvio padrão observados para DQ 0 foram de $25,40 \%$ e $25,14 \%$, respectivamente, valores estes fora da faixa citada pela literatura para o reator UASB, que é de 55 - 70\% (CHERNICHARO, 2007).

Esse fato pode ser atribuído tanto à descontinuidade de alimentação do reator UASB como ao processo ineficiente de inoculação de lodo ativo no início da operação do sistema, uma vez que, para que se tenha elevada atividade microbiológica na remoção da matéria orgânica, é necessária a retenção de significativa quantidade de biomassa ativa agindo no processo.

Quando observados os trabalhos de Chaves et al. (2018), Facin et al. (2018) e Dias et al. (2015), percebe-se que a eficiência do reator operado pela UFS, de fato, encontra-se distante dos valores ótimos apresentados na Tabela 5. Esses autores avaliaram reatores UASB em suas respectivas regiões e observaram valores de eficiência de remoção de matéria orgânica em termos de DBO ou DQO de $77 \%$, 75\% e 59,5\%, respectivamente.

No que se refere à fração de sólidos suspensos e sedimentáveis, o reator se mostrou eficiente. No entanto, para os sólidos totais, o reator mostrou baixa eficiência durante toda a campanha. Os valores de média e desvio padrão foram de 9,67 mg. $\mathrm{L}^{-1}$ e 11,33 mg. $\mathrm{L}^{-1}$, respectivamente. Esses valores mostram que poderia haver perda de sólidos junto com o efluente. No entanto, o que foi percebido, de fato, foi que a não alimentação do reator de forma contínua pode ser crucial para a não formação da manta de lodo e, consequentemente, a baixa concentração de sólidos no sistema, uma vez que os sistemas anaeróbios são sensíveis a variações de vazão afluente.

Sendo assim, a descontinuidade pode estar sendo influenciada tanto pela falta de algum dispositivo ou sistema para regularização da vazão a montante do reator (uma vez que o sistema possui períodos de pouca ou nenhuma geração de esgoto, como noite, finais de semana e feriado) como pela falta de regularidade operacional na 
limpeza das etapas de pré-tratamento, influenciando de forma negativa a eficiência do sistema.

Na Fig. 2 é apresentado o diagrama de extremos para a remoção de $\mathrm{DQO}$ e sólidos no reator UASB da estação de tratamento da Universidade Federal de Sergipe. Para nenhum dos parâmetros citados na Fig. 2 foram apresentados outliers. Para a DQO e ST, o limite superior es- teve mais distante da mediana, enquanto para SS e SSED esse limite superior apresentou-se mais próximo da mediana. Essa mediana esteve mais próxima do terceiro quartil (75\% dos dados) para os parâmetros DQO e SS, enquanto para os ST e SSED a mediana esteve próxima do primeiro quartil, ou seja, mais próxima dos $25 \%$ dos dados para esses parâmetros.

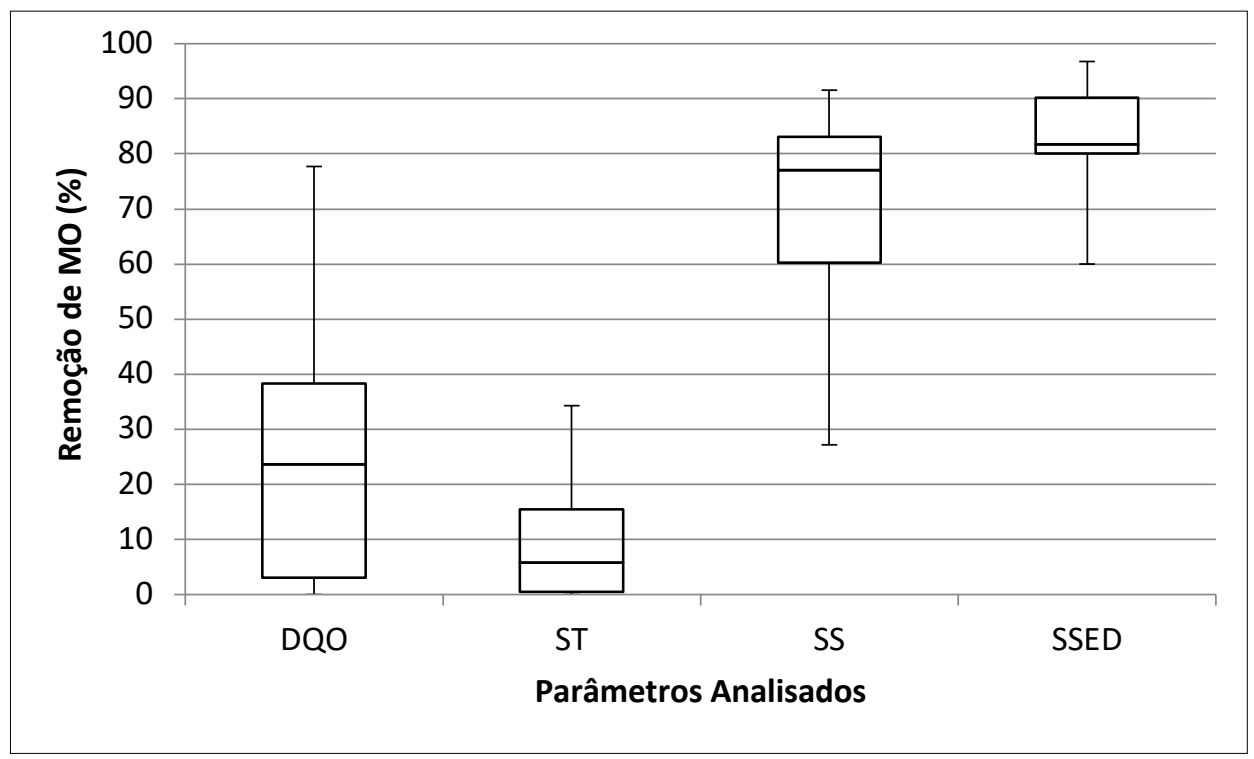

Figura 2 - Diagrama de Extremos de remoção de matéria orgânica (\%)

\subsection{Temperatura e $\mathrm{pH}$}

O controle desses parâmetros tem papel fundamental devido à efetiva influência no crescimento dos microrganismos no interior do reator. As Fig.s 3 e 4 apresentam gráficos de linha com os valores para temperatura e $\mathrm{pH}$, respectivamente, tanto afluente como efluente ao reator UASB.
A partir da Fig. 3 pode ser verificado que a temperatura varia entre 27 e $30^{\circ} \mathrm{C}$, sendo que a média observada para esse parâmetro é de $28,2{ }^{\circ} \mathrm{C}$ para o afluente e $27,8^{\circ} \mathrm{C}$ para o efluente. Essa configuração se mostrou dentro do esperado de acordo com Metcalfe Eddy (2015), os quais citam que a temperatura ótima para as atividades bacterianas é na faixa de 25 a $35^{\circ} \mathrm{C}$. 


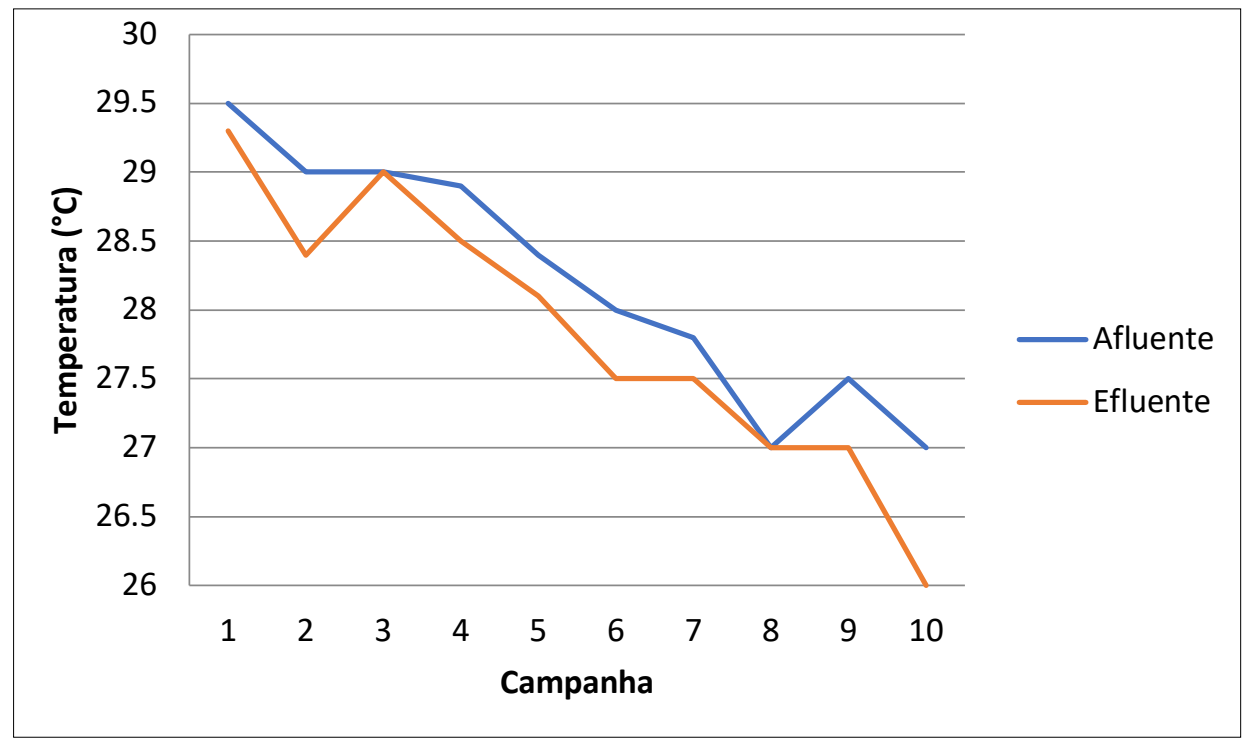

Figura 3 - Valores de temperatura no afluente e efluente do reator UASB

Já os valores de $\mathrm{pH}$ apresentaram variação entre 6,8 e 8,2, como visto na Fig. 4, sendo assim apresentam-se de acordo com o que é citado por Chernicharo (2007), na qual as bactérias metanogênicas têm crescimento ótimo na faixa de $\mathrm{pH}$ entre 6,6 e 7,4, embora possa-se conseguir estabilidade na formação de metano numa faixa mais ampla de $\mathrm{pH}$, entre 6,0 e 8,0. Valores de $\mathrm{pH}$ abaixo de 6,0 e acima de 8,3 devem ser evitados. $\mathrm{O} \mathrm{pH}$ ótimo depende do tipo de microrganismos envolvidos no processo de digestão, como também do tipo de substrato.

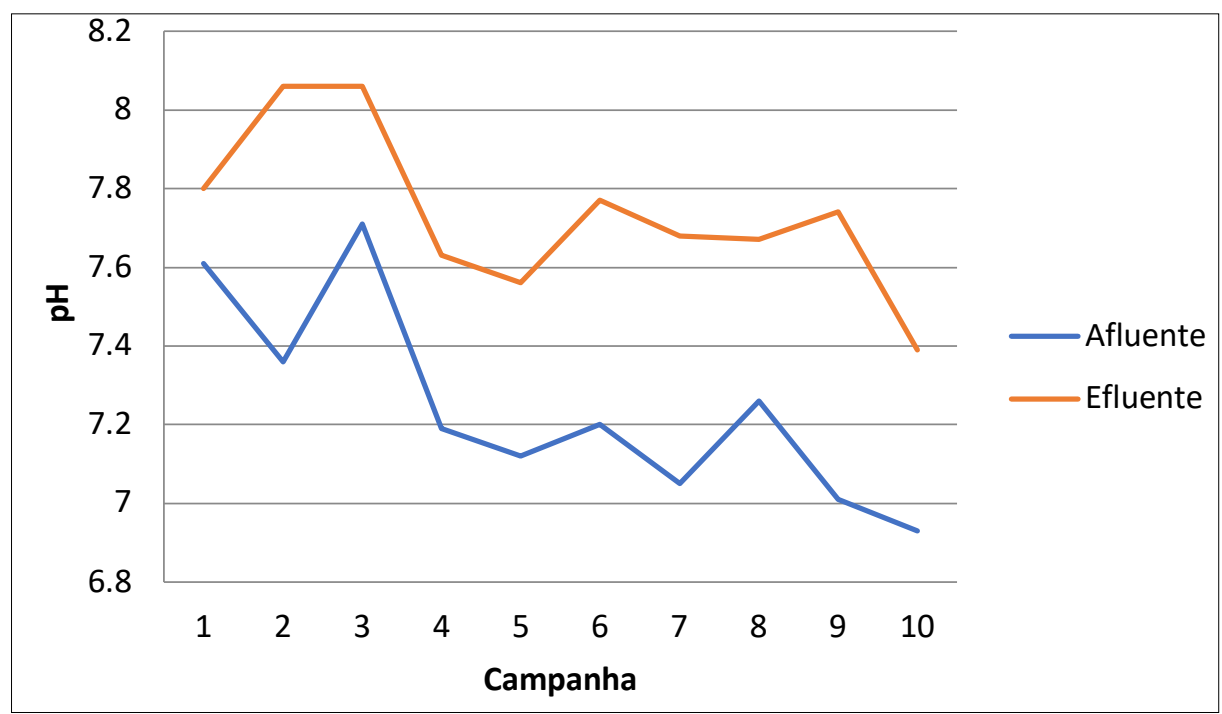

Figura 4 - Valores de $\mathrm{pH}$ no afluente e efluente do reator UASB 


\subsection{Remoção de Nutrientes}

A quantidade requerida de cada nutriente é variável, o que não o torna menos importante. Se o nutriente em questão não atingir essa quantidade requerida, pode limitar o crescimento da massa microbiana. No entanto, se o nutriente exceder essa quantidade, pode assumir características tóxicas e inibir o crescimento da massa microbiana. O nitrogênio $(N)$ e o fósforo $(P)$ são os nutrientes essenciais para todos os processos biológicos. A quantidade de $\mathrm{N}$ e $\mathrm{P}$, em relação à matéria orgânica presente, depende da eficiência dos microrganismos em obter energia para síntese, a partir das reações bioquímicas de oxidação do substrato orgânico. A baixa velocidade de crescimento dos microrganismos anaeróbios, comparados aos aeróbios, resulta em menor requerimento nutricional (BERTOLINO, 2007).

A Fig. 5 apresenta a remoção de nutrientes no reator UASB da ETE/UFS. Por meio da Fig. 5, percebeu-se que a média e o desvio padrão observados para o nitrogênio foram de 2,91\% e 3,11\%, respectivamente. Já para o fósforo pôde-se observar valores de 14,7\% para média e 10,36\% para o desvio padrão. Segundo Chernicharo (2007), os reatores UASB possuem entre suas desvantagens a insatisfatória remoção de nitrogênio e fósforo. Logo, por meio da observação da Fig. 5 pode-se notar a baixa eficiência do reator UASB em termos de remoção desses parâmetros.

Outra assertiva que deve ser levada em consideração se refere ao fato de que a relação de nutrientes provenientes das águas residuárias tem grande importância em diversos fatores dentro do reator. $O$ nitrogênio e o fósforo (macronutrientes) são necessários para manter a estabilidade e alta performance da digestão anaeróbia e, por consequência, altas taxas de produção de metano (WEILAND, 2010 Apud GABARDO, 2016).
Por meio da observação da Fig. 5 pode-se notar que para o nitrogênio o limite superior esteve mais distante da mediana, enquanto para o fósforo esse limite superior apresentou-se mais próximo da mediana. Vale ressaltar que para nenhum dos parâmetros avaliados na Fig. 5 observou-se a presença de outliers, sendo que a mediana para o fósforo foi cerca de dezessete vezes maior do que a mediana do nitrogênio.

Os valores registrados para as medianas do fósforo e nitrogênio foram de 17,36\% e 1,54 \%, respectivamente. Foi observado também que a mediana para o fósforo esteve mais próxima ao terceiro quartil (75\% dos dados), enquanto para nitrogênio a mediana esteve próxima ao primeiro quartil, ou seja, mais próxima dos $25 \%$ dos dados para esses parâmetros.

Sendo assim, a descontinuidade na alimentação do reator, como já foi citado anteriormente, pode estar afetando diretamente a produção de biogás, pois, uma vez que se tem pouco substrato, tem-se poucos nutrientes e, consequentemente, baixa performance do reator, fato observado no reator UASB em estudo.

Os trabalhos de Chaves et al. (2018) e Facin et al. (2018), que abordam eficiência de reator para remoção de nitrogênio e fósforo total, foram comparados com os dados do reator operado pela UFS, do qual percebeu-se que os dados do atual estudo não se aproximam dos valores ótimos apresentados pelos autores supracitados, tampouco com os valores observados na Tabela 5. Chaves et al. (2018) observaram valores de eficiência de remoção de nutrientes em termos de nitrogênio total e fósforo total de $26 \%$ e $36 \%$, respectivamente, enquanto para Facin et al. (2018) os dados de remoção foram de $29 \%$ e $52 \%$, respectivamente. 


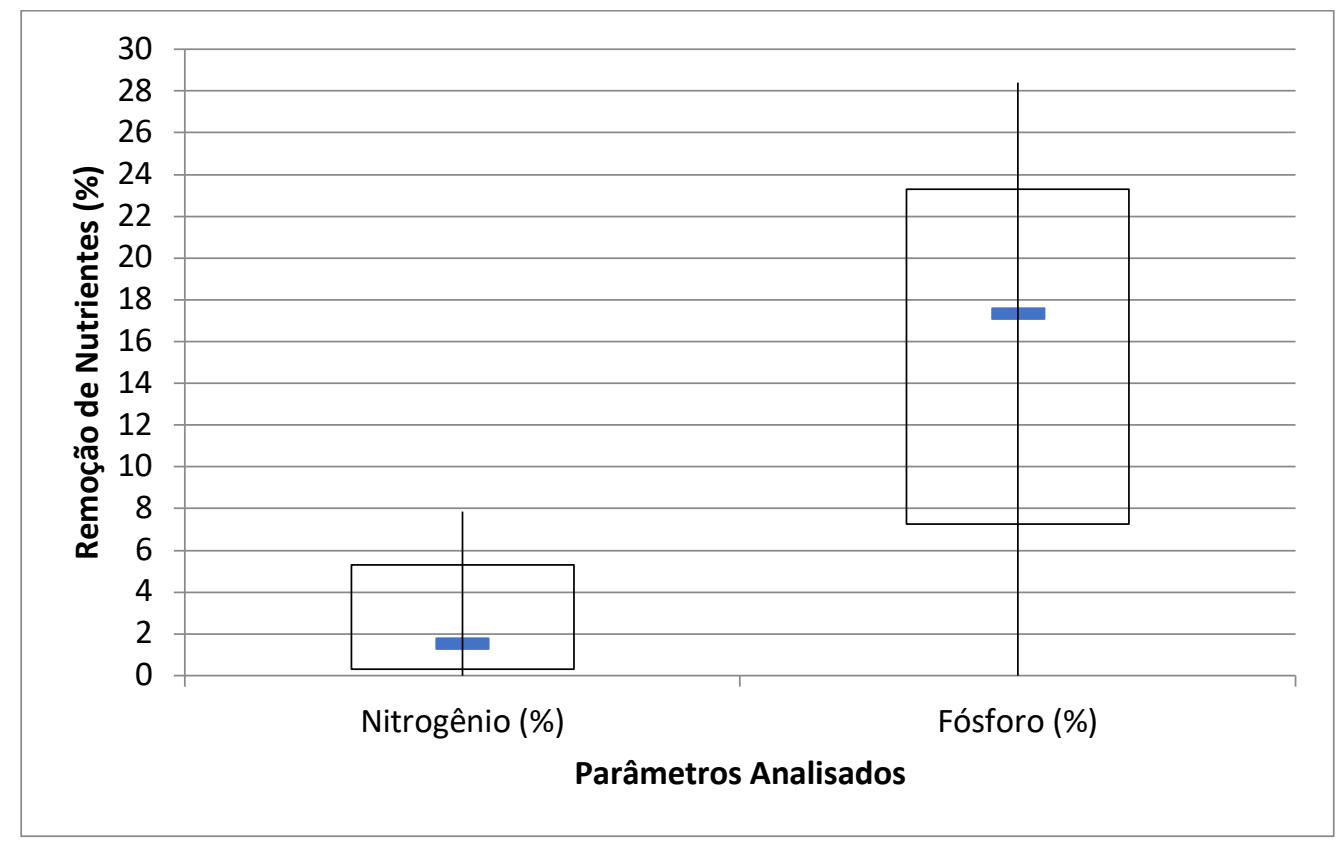

Figura 5 - Diagrama de Extremos de remoção de nutrientes

\subsection{Critérios de Projeto}

Para determinar a CHV, considerou-se a vazão média afluente ao reator de $183,17 \mathrm{~m}^{3} \cdot \mathrm{dia}^{-1} \mathrm{e}$ o volume do reator de acordo com o projeto de $457,03 \mathrm{~m}^{3}$, obtendo-se assim $0,4 \mathrm{~m}^{3} \cdot \mathrm{m}^{-3} \cdot \mathrm{d}^{-1}$. Estudos experimentais demonstraram que a CHV não deve ultrapassar o valor $5,0 \mathrm{~m}^{3} / \mathrm{m}^{3}$.d, o que equivale ao TDH mínimo de 4,8 horas para temperatura superiores a $26^{\circ} \mathrm{C}$ (CHERNICHARO, 2007).

Com relação ao $\mathrm{TDH}$, obteve-se 2,5 dias, o que equivale a $60 \mathrm{~h}$. Logo, percebe-se que este parâmetro se apresenta em demasiado desacordo com o sugerido pela literatura, uma vez que o projeto do reator em questão apresenta-se superdimensionado.

Por fim, em relação à velocidade ascensional, Chernicharo (2007) recomenda 0,5 - 0,7 m.h-1, pois quando o fluxo ascendente é significativo pode provocar o arraste excessivo de partículas do lodo, levando à diminuição da eficiência do sistema. A velocidade superficial máxima no reator depende do tipo de lodo presente e das cargas aplicadas. Foi utilizado o valor de vazão média afluente ao reator de $7,63 \mathrm{~m}^{3} \cdot \mathrm{h}^{-1}$. Além disso, a área da seção transversal de acordo com o projeto é de $100 \mathrm{~m}^{2}$, o que resultou em $0,076 \mathrm{~m} \cdot \mathrm{h}^{-1}$, sendo esta muito abaixo do recomendado pela literatura. Tal fato relaciona-se com as baixas vazões observadas do afluente assim como à descontinuidade na alimentação do reator citada anteriormente.

\section{CONCLUSÃO}

O presente trabalho possibilitou avaliar os aspectos técnicos e operacionais do sistema UASB. Por se tratar de um sistema recente e com um defasado histórico de dados qualitativos do efluente, a realização dos ensaios físico-químicos, complementados pelas visitas à ETE e entrevista com os operadores, permitiram-nos fazer um diagnóstico apurado do sistema.

Observou-se que o reator do Campus de São Cristóvão apresentou baixa eficiência na remoção de matéria orgânica e nutrientes, cerca de $25,4 \%$ e $3 \%$, respectivamente. Os resultados 
obtidos no presente estudo demonstram que a realidade operacional atual do sistema pode ser atribuída tanto à descontinuidade de alimentação do reator UASB como ao processo ineficiente de inoculação de lodo ativo no início da operação do sistema, uma vez que, para que se tenha elevada atividade microbiológica na remoção da matéria orgânica e nutriente é necessária a retenção de significativas quantidades de biomassa ativa agindo no processo.

Além disso, os parâmetros operacionais CHV, TDH e velocidade ascensional demonstraram que as condições atuais do reator se apresentam em desacordo com as exigências requeridas no projeto inicial. Os valores observados foram de $0,4 \mathrm{~m}^{3} \cdot \mathrm{m}^{-3} \cdot \mathrm{d}^{-1}, 60 \mathrm{~h}$ e $0,076 \mathrm{~m} \cdot \mathrm{h}^{-1}$, respectivamente. Verificou-se que a ETE está pouco carregada hidraulicamente, possibilitando a verificação de uma baixa eficiência na remoção, principalmente, de matéria orgânica, quando associada a valores apresentados na literatura, muito provavelmente pelo aumento do tempo de detenção hidráulica.

\section{CONTRIBUIÇÃO DOS AUTORES}

Conceitualização, Santos LVA; Metodologia, Santos LVA e Michelan DCGS.; Investigação, Santos LVA, Oliveira SS e Souza ASN; Redação - Primeira versão, Santos LVA; Redação - Revisão \& Edição, Santos LVA e Michelan DCGS; Aquisição de Financiamento, Santos LVA, Oliveira SS e Souza ASN; Recursos, Santos LVA, Oliveira SS, Souza ASN e Michelan DCGS; Supervisão, Santos LVA e Michelan DCGS.

\section{REFERÊNCIAS}

ANA - Agência Nacional De Águas. Atlas Esgotos: despoluição de bacias hidrográficas. Agência Nacional de Águas, Secretaria Nacional de Saneamento Ambiental., Brasília, 2017.

APHA - American Public Health Association. Standard methods for the examination of water and wastewater $\left(22^{\mathrm{a}} \mathrm{ed}\right.$.), 2012.
ARAÚJO, A. P. C. S; FREITAS, B. de O. Remoção de matéria orgânica e oxidação do nitrogênio amoniacal presente em esgoto sanitário por sistema combinado UASB e biofiltro aerado submerso. Enciclopédia Biosfera, v. 10, n. 19, p.1642-1655, 2014.

BERTOLINO, S, M. Caracterização e tratabilidade dos esgotos produzidos pelo campus da universidade federal de Ouro Preto - MG. 2007. Dissertação (Mestrado em Engenharia Ambiental) - Programa de Pós Graduação em Engenharia Ambiental, Universidade Federal de Ouro Preto, Minas Gerais, 2007.

BRASIL. Secretaria Nacional de Saneamento Ambiental. Probiogás. Guia técnico de aproveitamento energético de biogás em estações de tratamento de esgoto. Probiogás - Brasília, DF: Ministério das Cidades, 2015. p.183.

BRASIL. Resolução $n^{\circ} \mathbf{4 3 0}$ de $\mathbf{1 3}$ de maio de 2011. Dispõe sobre as condições e padrões de lançamento de efluentes, complementa e altera a Resolução no 357, de 17 de março de 2005, do Conselho Nacional do Meio Ambiente - CONAMA. Brasília, 2011.

CAMPOS, J. R. et al. Tratamento de esgotos sanitários por processo anaeróbio e disposição controlada no solo. $1^{\text {a }}$ ed. Rio de Janeiro, 1999.

CHAVES, V. S.; SCHNEIDER, E. H.; LIMA, A. S. P.; MENDONÇA, L. C. Desempenho das estações de tratamento de esgoto de Aracaju. Revista DAE. v.66, n. 209, p.51-58, 2018. http://doi. org/10.4322/dae.2017.014

CHERnicharo, C. A. L. Princípios do Tratamento Biológico de Águas Residuárias: Reatores Anaeróbio, $2^{\mathrm{a}}$ ed. Belo Horizonte, 2007.

CHERNICHARO, C. A. L. et al. Anaerobic Sewage Treatment in Latin America. World Scientific. London, 2015. https://doi. org/10.1142/9781783267910_0012

CHERNICHARO, C. A. L. Post-Treatment Options for the Anaerobic Treatment of Domestic Wastewater. Environmental Science and Bio/Technology, v. 5, n. 1, p. 73-92, 2006. http://doi. org/10.1007/s11157-005-5683-5

CHONG, S. et al. The performance enhancements of upflow anaerobic sludge blanket (UASB) reactors for domestic sludge treatment - A State-of-the-art review. Water Research. v. 46, n. 11, p.3434-3470, 2012. http://doi.org/10.1016/j.watres.2012.03.066

DIAS, D. F. C.; PASSOS, R. G.; RODRIGUES, V. A. J.; MARTINS, L. J.; SPERLING, M. Desempenho de sistema de tratamento de esgoto para pequenas comunidades composto por reator UASB, lagoas de polimento em série (lagoa sem chicana e lagoa com chicana) e filtro grosseiro de pedra. In: XXVIII Congresso Brasileiro de Engenharia Ambiental e Sanitária. Rio de Janeiro, 2015. Anais...

FACIN, F.; CABRAL, C. B. G.; FILHO, P. B.; LAMIN, P. C. Avaliação operacional de ETE composta por reator UASB seguido de biofiltro aerado submerso, um estudo de caso em ETE de escala real 
no município de Luzerna-SC. In: XLVIII Congresso Nacional de Saneamento da ASSEMAE. Fortaleza, 2018. Anais...

GABARDO, R. A. Influência da relação C:N:P no desempenho de reatores tipo UASB. Dissertação (Mestrado em Engenharia Civil) - Programa de Pós Graduação em Engenharia Civil, Universidade Tecnológica Federal do Paraná, Curitiba, 2016.

HELLER, L.; NASCIMENTO, N. O. Pesquisa e desenvolvimento na área de saneamento no Brasil: necessidades e tendências. Revista ABES, v.10, n. 1, p. 24-35, 2005. https://doi.org/10.1590/ S1413-41522005000100004

MENEZES, S. I. Avaliação do tratamento preliminar da Estação de Tratamento de Efluentes do Campus de São Cristóvão da UFS. Trabalho de Conclusão de Curso - Programa de Graduação em Engenharia Civil, Universidade Federal de Sergipe, São Cristóvão, 2016.54p.

METCALF, L; EDDY, H. P. Tratamento de efluentes e recuperação de recursos. $5^{\text {a }}$ ed. São Paulo, 2015.

METCALF, L; EDDY, H. P. Wastewater Engineering: Treatment and Resource. Recovery. $5^{\mathrm{a}}$ ed. New York, 2014.

JORDÃO, E. P.; PESSÔA, C. A. Tratamento de Esgotos Domésticos. $6^{\mathrm{a}}$ edição. Rio de Janeiro, 2014.

LEME, E. J. DE A. Manual prático de tratamento de águas residuárias. $2^{\mathrm{a}}$ ed. São Carlos. 2014.

NUVOLARI, A; TELLES, D. D; RIBEIRO, T; MIYASHITA, N. J; RODRIGUES, R. B; ARAUJO, R; MARTINELLI, A. Esgoto sanitário: coleta, transporte, tratamento e reúso agrícola. $2^{\mathrm{a}}$ ed. São Paulo, 2011.

PASSIG, F. H. Reator anaeróbio híbrido para tratamento de esgoto sanitário. Tese (Doutorado em Engenharia Hidráulica e Saneamento) - Programa de Pós Graduação em Engenharia Civil, Escola de Engenharia de São Carlos, São Paulo, 2005.
PEIXOTO, M. S. Avaliação técnica e operacional da estação de tratamento de esgotos por lodos ativados do campus do Pici da Universidade Federal do Ceará. Dissertação (Mestrado em Engenharia Civil) - Programa de Pós Graduação em Engenharia Civil, Universidade Federal do Ceará, Ceará, 2008.

SILVA, Z. F. B. Cenário atual da secção urbana do Rio Poxim. Dissertação (Mestrado em Gestão de Recursos Hídricos e Meio Ambiente) - Programa de Pós Graduação em Desenvolvimento e Meio Ambiente, Universidade Federal de Sergipe, São Cristóvão, 2001.

SNIS - Sistema Nacional de Informações sobre Saneamento. Diagnóstico dos serviços de Água e Esgoto - 2017. SNIS. Brasília,2019.

TAUCHEN, J; BRANDLI, L. L. A gestão ambiental em instituições de ensino superior: modelo para implantação em campus universitários. Revista Gestão e Produção, v. 13, n.3, p. 503-515, 2006. https://doi.org/10.1590/S0104-530X2006000300012

VERSIANI, B. M. Desempenho de um reator UASB submetido a diferentes condições operacionais tratando esgotos sanitários do Campus da UFRJ. Dissertação (Mestrado em Engenharia Civil) - Programa de Pós Graduação em Engenharia Civil, Universidade Federal do Rio de Janeiro, Rio de Janeiro, 2005.

VON SPERLING, M. Princípios do tratamento biológico de águas residuárias: Introdução à qualidade das águas e ao tratamento de esgotos. $4^{\mathrm{a}}$ ed. Belo Horizonte, 2014.

VON SPERLING, M.; OLIVEIRA, S. C. Comparative performance evaluation of full-scale anaerobic and aerobic wastewater treatment processes in Brazil. Water Science \& Technology. v.59, n.1, p. 15-22, 2009. https://doi.org/10.2166/wst.2009.841

WWAP - UNITED NATION WORLD WATER ASSESSMENT PROGRAMME. Wastewater: the untapped resource. Paris, 2017. 